\title{
Late development Nicolau Syndrome: A case report
}

\author{
Alyne Mendonca Marques Ton ${ }^{1}$, Angelo Ton ${ }^{2}$, Thaisa Faustini Loureiro ${ }^{1}$ and Brunella Lemos Agrizzi ${ }^{1}$ \\ ${ }^{1}$ Undergraduate Medical Student - Faculdade Brasileira (UNIVIX) - Vitória (ES), Brazil \\ ${ }^{2}$ Veterinarian - Centro Universitário Vila Velha (UVV) - Vila Velha (ES), Brazil
}

\begin{abstract}
The Nicolau Syndrome, also known as embolia cutis medicamentosa and lived o-like dermatitis, is a rare complication, manifested as tissue necrosis following an injection. We describe a case of late development Nicolau Syndrome following intra-articular infiltration of corticoid.
\end{abstract}

\section{Introduction}

Glucocorticoid infiltration is one of the procedures more commonly performed in rheumatology. Despite the fact that glucocorticoid therapy generates a variety of side effects, both localized and systemic, it is frequently considered a safe procedure $[1,2]$.

Localized glucocorticoid injections are widely applied for treating patients who suffer from muscular-skeletal diseases. Infectious complications are the main source of concern, but they remain rare [3].

Here two cases of Nicolau Syndrome post intra-articular glucocorticoid injections are described [3]. According to Cherasse et al. (2003), developing the Syndrome under such circumstances is rare. However, studies regarding the position of the needle during the injections, which was supposed to be intra-articular, showed that the needle was usually totally or partially outside of the joint space [3].

Below there is a report by a patient who underwent two intraarticular glucocorticoid infiltrations and then developed a late Nicolau Syndrome condition.

\section{Case report}

The patient, 47 years old, female, hypertensive, suffered a sprained ankle, $3^{\text {rd }}$ degree, in November of 2008, which evolved into a painful edema in the lateral face of the ankle, with functional impotence for walking, limited mobility and extensive localized erythema.

She immediately sought orthopedic assistance and was diagnosed, through a Magnetic Resonance exam, with a partial rupture in the stem-fibular ligament and tenosynovitis of the fibulas with slight rupturing of the short fibular and acute liquid distension of the synovial sheath. Painkillers and anti-inflammatories were prescribed, without immobilizing the joint. Since the edema and the pain did not disappear after 5 months, the patient underwent 2 infiltration procedures in the fibular sheaths with retinaculotomy of the extensors using a percutaneous approach, within a seven-day interval. It improved with reduction of the edema and control of the pain.

After 1 week, the patient started to develop a condition of strong burning pain in the area of the infiltration, without any aggravating or extenuating factors, and associated to the manifestation of a necrosis area restricted to the left maleolar region, measuring approximately 2 $\mathrm{cm}$ in diameter (Figure 1). She sought assistance from an emergency service and was medicated with painkillers while being monitored hemodynamically.

About 72 hours later the condition evolved with spread of the necrosis and irregular borders, exanthema erythematosus in the limb with the presence of a halo of erythema surrounding the lesion, and aggravated pain. She was then committed to Vila Velha Hospital where she underwent an Eco Doppler exam of the lower limbs, showing no alterations. She was then diagnosed with Nicolau Syndrome and medicated with ciprofloxacin, enoxaparin and pentoxifilin.

Next, a surgical debridement was performed in the devitalized tissue, exposing the sinew (Figure 2). The wound improved, developing atrophic scarring 3 months after the surgery (Figure 3 ).

\section{Discussion}

Nicolau Syndrome, or Embolia Cutis Medicamentosa, was first described by Juliusberg, Freudenthal and Nicolau between 1924 and 1928 [3-6]. The first descriptions refer to patients undergoing treatment for syphilis who received injections of bismuth salts.

It is well described in dermatologic literature as a rare side effect characterized by livedoid dermatitis [3-5,7] which occurs after the intra-muscular injection of insoluble substances [4,7-9]

Nevertheless, the emergence of the Syndrome is associated with the route of administration and the new pharmaceutical formula of the drug, rather than with its pharmacodynamic properties, and consequently, there is not a specific group responsible for the complication potential. A systematic review showed that predisposing factors, such as watery micro-suspension in the vehicle, in opposition to oily, suggesting a prevalent genesis of the Syndrome's embolism [10]

Nicolau Syndrome has already been described with the administration of many other drugs, such as benzathine penicillin,

Correspondence to: Alyne Mendonça Marques Ton, Rua Dr Juvino Leal Andrade - 03, Tabuazeiro, 29.043-364 Vitória - ES, Brazil, Tel: 278134 7065; E-mail: lyne_msv@hotmail.com

Key words: glucocorticoids, necrosis, dermatitis

Received: February 05, 2015; Accepted: March 07, 2015; Published: March 09, 2015 


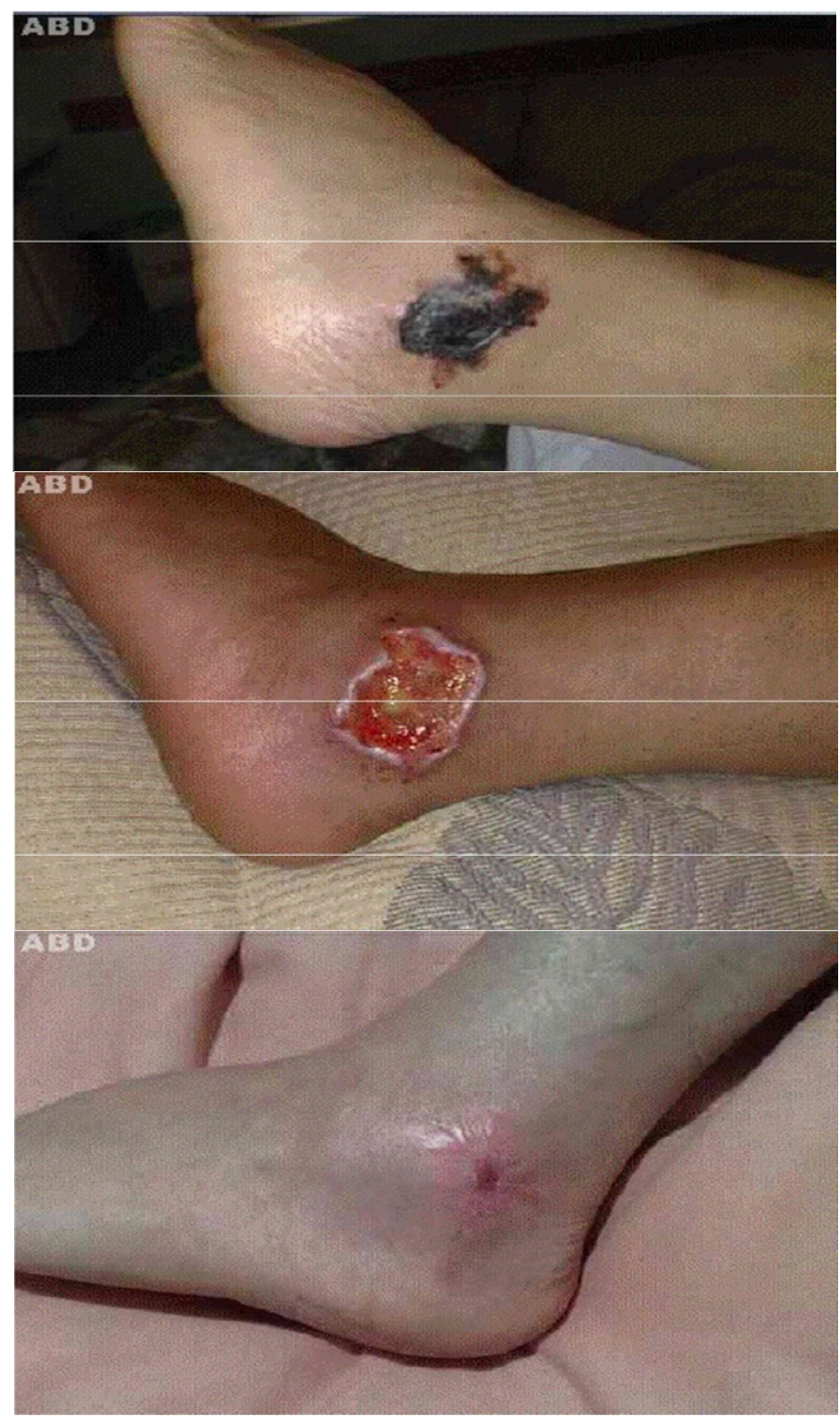

Figure 1. A. Circumscribed area of necrosis in the left malleolar region; B. Lesion after surgical debridement, with exposure of ten-don; C. Atrophic scar.

penicillin, non-steroid anti-inflammatories, local anesthetics, antihistamines, penicillin and glucocorticoids [5].

According to Saputo \& Bruni (1998) this Syndrome is more recurrent among the pediatric population, specially three-year-old children and younger, in whom the penetration phenomena caused by embolism in the artery can be more likely, due to the smaller size of the vascular segments involved [10]. According to Senel et al. (2008), however, most of the published reports refer to adults [5].

Despite the fact that the gluteus is more often the affected region, it has been also described as present in the shoulder, thigh, knee and ankle [5].

The mechanism of inflammation and cellular destruction is uncertain, but we know that a micro embolic obstruction of the arterial blood supply occurs in the dermis $[4,10,11]$.

Data that are more recent suggest, however, that embolism is not the only factor involved. Apparently, the final lesion derives from the combination of three factors: vasospasm, thrombosis and embolism [11].

Embolism and thrombosis appear to be caused by injecting the medication within the vascular lumen, while vasospasm could be caused by a series of factors, such as compression of the vessel (by the liquid injected or by a hematoma), a direct lesion in the vessel caused by the needle or by arterio-arterial or venous-arterial reflexes $[7,11]$.

There are, moreover, authors who believe in an immune-allergic origin to explain the necrosis $[10,11]$. According to them, the drug in question would act as a hapten, unleashing a vasculite-like reaction, with the deposition of imunocomplexes, complement activation and neutrophil chemotaxis. The result of these alterations would be thrombosis, which clinically manifests itself as necrosis [11].

Clinical signs can be localized or systemic. Initially, the patient manifests a serious, acute and severe pain after the injection $[3,5,7,8,10]$. Afterwards, comes the development of an exanthema erythematosus around the injected area [10], with the formation of a halo of pallor surrounding the region, and of a livedoid pattern [3,5,12], which slowly evolves into skin necrosis, subcutaneous, e sometimes, muscular $[10,13]$.

In some patients, it can evolve into blisters in the injection site, with the possibility of a secondary infection $[3,5,7]$. In a few cases, the necrotic area can spread to the joint, causing a transitory or permanent ischemia, which sometimes requires amputation [10].

A third of the patients present neurological complications, usually transient (a few hours to several weeks), namely hypoesthesia and paraplegia $[10,13]$.

The lesion in the tissue is reversible and quick working therapy with vasoactive substances such as subcutaneous heparin has proven to be beneficial [14].

Vasospasm can be alleviated through phosphodiesterase's inhibitive action as provided by pentoxifilline [10].

Corroborating the data according to Uri and arad (2009), various studies mention the clinical improvement of the patient through the administration of anticoagulant agents (i.e. heparin), intravenous steroids (i.e. Intravenous betamethasone, dexamethasone or methylprednisolone) and vasoactive therapy (i.e. pentoxifilline) [14].

According to Murthy, Siddalingappa and Suresh (2007), the conservative treatment with debridement and pain control constitute the main therapy [14].

Taking into consideration the fact that there is no established standard for treating Nicolau Syndrome, it is important to employ the correct technique during the injection to minimize risk factors.

Previous aspiration is important in order to make sure the injection is administered in an extra-articular area, even though there are no specific guidelines [15].

\section{References}

1. Hajjioui A, Nys A, Poiraudeau S, Revel M (2007) Complication inhabituelle des infiltrations de corticostéroïdes: le syndrome de Tachon. À propos de deux cas cliniques. Annales de readaptation et de médicine physique 50: 718-720.

2. Beissert S, Presser D, Rütter A, Metze D, Luger TA, et al. (1999) Embolia cutis medicamentosa (Nicolau syndrome) after intraarticular injection. Hautarzt 50: 214 216. [Crossref] 
3. Cherasse A, Kahn MF, Mistrih R, Maillard R, Strauss J, et al. (2003) Nicolau's syndrome after local glucocorticoid injection. Joint Bone Spine 70: 390-392.[Crossref]

4. de Sousa R, Dang A, Rataboli P (2008) Nicolau syndrome following intramuscular benzathine penicillin. J Postgrad Med 4: 332-334. [Crossref]

5. Senel E, Ada S, Gülec AT, Çaglar B (2008) Nicolau syndrome aggravated by cold application after i.m. diclofenac. J Dermatol 35: 18-20. [Crossref]

6. Masthan SD, Salome, Madhav, Reddy K, Sridevi, et al. (2002) Nicolau syndrome. Indian J Dermatol Venereol Leprol 68: 45-46. [Crossref]

7. Hamilton B, Fowler P, Galloway H, Popovic N (2008) Nicolau syndrome in an athlete following intramuscular diclofenac injection. Acta Orthop Belg 74: 860-864. [Crossref]

8. Gayken J, Westanmo A, Knutsen A, Ahrenholz D, Mohr WJ, et al. (2006) Livedoid dermatitis and severe necrosis (Nicolau's syndrome) after intramuscular hydroxyzine injection. Journal of Burn Care \& Research 27: 54144.

9. Mutalik S, Belgaumkar V (2006) Nicolau syndrome: a report of 2 cases. $J$ Drugs Dermatol 5: 377-378. [Crossref]
10. Saputo V, Bruni G (1998) Nicolau syndrome from penicillin preparations: a review of the relevant literature in the search for potencial risk factors. Pediatric Med Chir 20: 105-123. [Crossref]

11. Golcman B, Golcman R, Castro LGM, Mizoguchi M (1991) Necrose tecidual após injeção intramuscular de diclofenaco de sódio: relato de 4 casos. Anais Brasileiros de Dermatologia 66: 669

12. Duval A, Pouchot J (2008) Livedo: de la physiopathologie au diagnostic. La Revue de medicine interne 29: 38092 .

13. Lie C, Leung F, Chow SP (2006) Nicolau syndrome following intramuscular diclofenac administration: a case report. J Orthop Surg (Hong Kong) 14: 104-107. [Crossref]

14. Murthy SC, Siddalingappa K, Suresh T (2007) Nicolau's syndrome following diclofenac administration: a report of two cases. Indian J Dermatol Venereol Leprol 73: 429-431.

15. Uri O, Arad E (2009) Skin necrosis after selfadministered intramuscular diclofenac. $J$ Plast Reconstr Aesthet Surg 63: e4-5. [Crossref]

Copyright: $(2015$ Ton AMM. This is an open-access article distributed under the terms of the Creative Commons Attribution License, which permits unrestricted use, distribution, and reproduction in any medium, provided the original author and source are credited. 